\title{
The Concept, Realizations and Role of Geosciences in the Development of Smart Cities
}

\author{
Zvonimir NEVISTIĆ*, Željko BAČIĆ
}

\begin{abstract}
Today, more than half of the world's population lives in cities and therefore the implementation of smart cities is being imposed as a strategy to solve the problems of rapid urbanization. Smart cities are still just a concept and there is no clear definition of it, and this paper provides a framework for understanding this concept and its key components. Considering a series of different studies, the basic components and factors of smart cities are derived. The implementation of this concept faces many challenges, with information and communication technology (ICT) playing a key role. Such cities are collecting large amounts of data, so in addition to ICT, two emerging technologies, the Internet of Things and the Big Data Concept, are increasingly being mentioned as the basis for successful development. Spatial information is also being imposed as one of the key drivers of successful development and decision making within a smart city. With the advancement and innovation of geospatial technologies, sciences such as geodesy and geoinformatics are becoming key drivers of the development of new smart applications and one of the essential components in the smart cities concept. But, due to the increasing interdisciplinarity of other sciences, geodesy and geoinformatics need to obtain their place in the concept of smart cities, so understanding this concept is crucial for sustainability of these professions.
\end{abstract}

Keywords: big data; geoscience; ICT; infrastructure; IoT; smart city

\section{INTRODUCTION}

The technological revolution has initiated the development of a whole new relationship to data and information and created new concepts of community management. Today we are talking about spatial data infrastructure as a fundamental concept of organization, primarily authoritarian data, and the Internet of Things (IoT), a concept that integrates, in a comprehensive way, sensors that collect data and solve process management problems on all levels. Many other application concepts are associated with this concept, such as the smart city. Smart cities are a relatively new concept that is not yet applicable on a larger scale and is the result of the fact that more than half of the world's population currently lives in cities [1]. Sudden urbanization is a global phenomenon, and in 2008, for the first time in human history, more people lived in cities than in rural areas. Current studies estimate that by $2030,60 \%$ of the human population will live in cities, with the highest growth expected in Africa, Asia and Latin America, or lower-income countries. This ratio could climb up to $2 / 3$ of the urban population by 2050 [2]. Also, the researches show that the growth of urban areas in the first three decades of the $21^{\text {st }}$ century will outstrip the total urban expansion in the past [3]. Given the above, it is not surprising that the UN Commission on Science and Technology for Development (CSTD) at its eighteenth meeting in May 2015 chose the concept of smart cities with associated infrastructure as one of the two most important topics for the coming period [2]. With further population growth, urban areas will become large and complex communities and unregulated places to live and will generate many problems. For example, cities around the world consume approximately $70 \%$ of the total global energy and production of greenhouse gas emissions, occupying just over 5\% of total surface area [4]. Problems also arise in terms of waste management, lack of resources such as food, water and energy, air pollution, climate change, endangering human health, traffic congestion, which will lead to inadequate infrastructure susceptible to deterioration and rapid aging. Also, the second group of problems that arise is more of economic, political, sociological and organizational type [1]. The realization of the concept of smart cities is proposed as a solution to these growing problems, and what was initially conceived as a technological utopia is becoming a necessary reality for cities today.

Thanks to technology development, cities have in recent years successfully transformed from passive consumers to proponents of innovative sustainability models. Ensuring reliable living conditions encourages many cities around the world to find innovative ways to manage them. Such cities are called "smart cities". One way to conceptualize a smart city is that it is a sustainable and life-friendly city, but today the frequency of using that term has increased sharply and there is still no clear and generally accepted concept.

This paper presents the concept, challenges, factors and infrastructure of smart cities through the research of extensive literature in various fields such as e-government, local governments, computer science and urban studies. There is a clear need for everyone, especially the technical professions, to find their place in the development and application of this concept and as a part of the digital revolution, geodesy and geoinformatics are also part of its implementation.

\section{SMART CITIES \\ 2.1 Definition and Concept}

There is no generally accepted definition of a smart city, and the term has different meanings for different groups of people and varies from city to city and state to state depending on the level of development, readiness for change and reforms, resources and aspirations of the population. A smart city would have a different connotation in Asia than in Europe, and even within one country, there is no single definition.

In 2014, the International Telecommunication Union (ITU) analyzed over one hundred different definitions of a smart city, resulting in the following: "A smart sustainable city is an innovative city that uses information and communication technologies (ICTs) and other means to improve quality of life, efficiency of urban operation and services, and competitiveness, while ensuring that it meets the needs of present and future generations concerning 
economic, social and environmental aspects" [5]. Several projects are currently under way to define unique and sustainable key performance and smart city indicators, led by a UN team of experts [2].

An analysis of different definitions of a smart city reveals that they emphasize different aspects of development, for example, according to one, a smart city is a city that combines physical infrastructure, information technology, social and business infrastructure to make the most of the collective intelligence of the city [6]. Another definition states that smart cities are those that use ICT technologies to increase the quality of life of their residents while enabling sustainable development [7], while according to Boyd Cohen, the success of a smart city lies in the development of infrastructure and the entire city should benefit from the integration of six components that intertwine and work as one - economy, environment, government, people, living and mobility [8]. The concept of a smart city provides different opportunities for different countries whereby smart infrastructure and its applications tend to be key responses to the sustainable needs of society. Developing countries, where the problem of construction cost and space arise, must focus on existing infrastructure and resources and make the most of them. Different definitions identify some common components that can be grouped into several thematic groups, and these are divided into several factors that make a city smart. Any combination of these components makes a city smart, and there is no need to satisfy all of them to become a smart city. The basic factors and components that a smart city must include as well as basic attributes of each smart city are shown in Fig. 1.

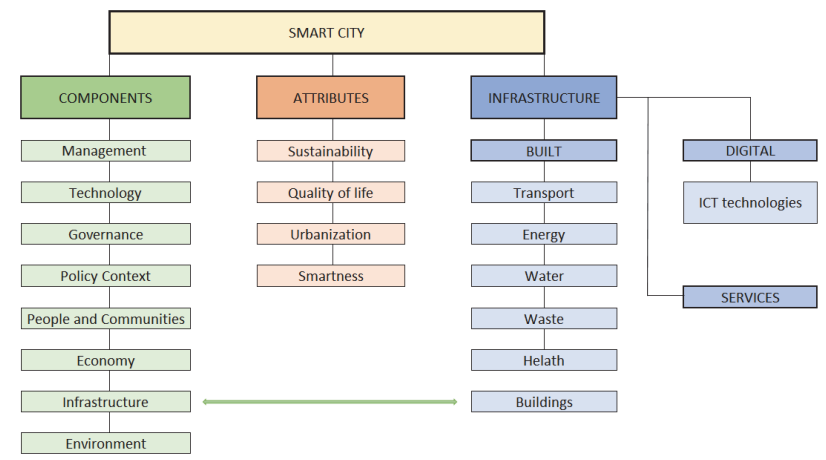

Figure 1 Components and factors of the smart city concept

Technology and infrastructure which is divided into built and digital (ICT solutions and services) are emerging as key factors in implementing the smart city concept. There are different priorities and needs for developing smart cities in different environments, while in some cities the main goal is to reduce traffic congestion, increase energy efficiency with smart grids or introduce e-governance methods; other cities look for ways to improve productivity and market competitiveness.

\subsection{Smart Cities Factors}

According to the definitions above, there are several important factors for understanding and implementing the concept of smart cities. These factors do not represent a set of parameters for smart cities ranking but can be used to study and determine the success of smart city initiatives and collected within a smart city framework they affect its design and implementation. Eight basic factors include management, technology, governance, policy concept, people and communities, economy, infrastructure and environment.

As one of the basic factors in smart city, only a few authors referred to management. It is considered within the context of e-Government and the success of ICT projects. The success of e-Government development depends on many challenges and strategies such as the size of the project itself, the diversity of users, project goals, the desire for change, the skills of the project implementers and ICT leaders, adequate education, funding, etc. [9].

Smart cities, among other things, rely on smart technologies that, integrated with infrastructure, provide services. The technologies used to apply to new generations of hardware, software and network technologies and include advanced analytics for smarter decision making and better living conditions for citizens. ICT technologies are the key to any smart city, and their integration can change the appearance of urban infrastructure and open new possibilities of using urban space and improve governance and life within the city [10]. When implementing ICT technologies, the availability of resources, capacities, institutional readiness and cultural habits must be considered to allow high-quality and efficient use of it.

Smart city development initiatives involve many stakeholders in the process, and as a result, there is an increased need for good leadership and management. The key role is played by the governance, which implements the process by following laws and standards in order to achieve the goals. Improvement in government is achieved through the integration of ICT technologies [11], and an important feature is the involvement of citizens and the private and public sectors in decision-making [12] as well as the willingness to change. Governance must be responsible, transparent and facilitate the co-operation and exchange of data and services.

The policy context represents a set of elements (city council, administration, etc.) and external factors that can influence the outcome of the initiative. Institutional readiness to remove legal regulations for the smooth implementation of smart city initiatives is a key policy element.

The people and community factor is also extremely important and yet it is often overlooked. The smart city project has a major impact on the quality of life and aims to encourage better information, education and involvement of citizens in urban activities. Initiatives like this encourage and allow citizens to participate in city governance. It is also important to address all communities and groups and their needs within the city.

The main driver of the smart city initiative is the economy, which is one of the key indicators of growth. A smart economy includes innovation, entrepreneurship, products and services, markets, productivity and business [12], and their outcomes are new business processes and technology sectors, job creation, workforce development and education, and productivity improvements.

Smart city infrastructure is a key factor in the development and implementation of the initiative, with ICT technology playing a major role. Without it, the 
concept of a smart city could not become reality. It includes wireless infrastructure such as Wi-Fi networks, wireless access points and Internet of Things and Big Data concepts. Also, an important role is played by built infrastructure and services that enable users to use these technologies. Implementing the right infrastructure is a basic prerequisite for smart city development and depends on several factors such as resource availability and capacity.

Smart cities also improve the environment. The concept itself is based on the use of technologies to increase sustainability and better manage natural resources. Of interest is also the protection of natural resources and the integration of infrastructure such as waterways, sewage and green spaces. Taken together, these factors have an impact on the sustainability and value of life in the city and should be considered within an initiative.

\section{SMART CITY INFRASTRUCTURE}

Smart infrastructure is the basis of every smart city. A key feature of smart solutions is the integration of all components and the generation of data and services to ensure optimal use of resources and improve the efficiency and better life of citizens. Smart city infrastructure can be divided into two categories: (1) physical or built, and (2) digital, which includes technological solutions that make physical components "smart" while providing numerous services to citizens.

\subsection{Physical (Built) Infrastructure}

City infrastructure can be expressed in various forms water, waste, buildings, transport, etc. Each element represents a separate system that is divided into several smaller components, devices and sensors, with the purpose to connect these systems and create communication and data networks with different ICT solutions.

For example, smart buildings integrate different components connected to a single system with ICT for better and efficient use and a more comfortable and secure life [4]. Such systems improve energy efficiency, reduce waste and costs, ensure optimal use of water and other resources, increase the building's operational capability by integrating various hardware, software, sensors and smart devices. Smart buildings make effective use of available knowledge and technologies outside their walls [6], they analyze large amounts of data and create urban spaces that can respond in real-time to human behavior and needs by providing the right services at the right time [13].

Smart transport is best described as an approach that reduces congestion and encourages faster, greener and cheaper transport [4]. Also, the goal of this infrastructure is to optimize city trips, save energy and reduce greenhouse gas emissions using a network of sensors, global positioning systems, dynamic lighting, communication devices, information desks, signaling, cameras, automatic billing systems and more. This system that integrates personal and city transport and all types of travel (road, rail, air and water) including various smart technologies is called the Intelligent Transport System (ITS). Some sensors in such systems are installed on the vehicles, and part of them is on the transport infrastructure allowing communication between the devices which increases the security, accessibility, comfort and reliability of the transport network with ICT and real-time data processing as a base [6].

Reducing energy consumption costs, energy security, non-renewable energy sources and global warming are one of the key tasks cities must deal with for sustainable development. Smart energy is being imposed as a major solution for this problem because it meets energy needs in an environmentally sustainable way by using long-term and cost-effective reduction [2]. Such systems use sensors, advanced meters, renewable energy sources, digital automated control and processing tools, they monitor and optimize energy consumption and use innovative infrastructure (virtual power plants, electric vehicles, etc.) [2], with ICT solutions and smart electricity delivery networks being the backbone [14].

Cities are making great efforts to address water scarcity by introducing new technologies and ways to manage and distribute water. Smart water management uses digital technologies and sensors for its conservation, continuous monitoring, cost reduction, remote problem diagnosis and decision making. The city's water supply network consists of a series of pipes that overlap with the communication data network. Such systems analyze realtime water availability, pressure, and anomaly detection (eg. water leakage) [4].

Also, waste production is growing faster than urbanization [15]. It is increasingly difficult for cities to find places to store, sort and recycle waste. Smart waste management systems reduce waste, sort waste at its source (consumers), enable the movement of different types of waste to be monitored, and develop methods for proper understanding and management of waste by reducing risks to health and the environment [4]. One of the basic inefficiencies of traditional waste management is the inability to predict when waste must be collected from a site. Trucks often find and collect empty containers. Sensors and ICT technology offer ways to mitigate the additional costs that arise from such inefficiencies.

Due to increased urbanization, traditional health care is flooded and there are not enough medical professionals to meet the needs of citizens. Smart cities, using technology and large amounts of data, can develop systems for predicting and monitoring the health of their citizens [16]. Smart health management collects citizens' health records into a unique database and provides health services, remote diagnoses, treatment and monitoring of patients, forecast of epidemic, taking precautionary measures. Such systems encourage the use of sensors and applications on smartphones to monitor vitality and support patient therapies, and hospitals use advanced data analytics, making patient data available in real-time across multiple hospitals within the same or different city [6].

\subsection{Digital Infrastructure}

Smart cities make optimum use of all available information for better understanding and control of business operations in the city, better management, use of limited resources and better sustainability and citizens' life. In this process, ICT plays a key role by creating a digital platform from which a network of information and knowledge can be created. One of the key values of ICT in 
a smart city is the ability to collect and share information promptly. If the information is accurate and timely, cities can potentially take preventative measures before the problem arises or escalates. In this context, a smart city can be understood as a "predictive city" where specific events and incidents can be predicted, which will result in improved quality of life and better-informed citizens [4]. The implementation of smart technologies often requires robust, reliable and affordable broadband Internet, an effective Internet of Things (IoT) system, and the ability to collect and utilize a large amount of data generated (Big data concept).

\subsubsection{Internet of Things}

Given the challenges facing the city, the EU and many other countries are investing in ICT research and innovation and developing policies to improve the quality of life of citizens in cities. With ICT technology, the core of a smart city's digital infrastructure is the implementation of the Internet of Things (IoT), which is a set of things (devices) that are connected and designed so that they can be managed wirelessly over the Internet using mobile apps. This way of connecting takes the whole concept of a smart city to a new level by providing new possibilities for interaction (communication) between different systems and enabling their control, monitoring and low energy consumption and high data flow services [17]. IoT is the one of the technical basis of smart cities, and this concept enables individuals, society and businesses to gain new access to large amounts of data, applications, data sharing and services to increase productivity, reduce costs and improve citizens' quality of life [18].

IoT can be conceptualized as a configurable global network made up of a series of smaller networks. According to Mohanty, there are four main components of IoT: things, local area network (LAN), internet and cloud. Under "things" here are considered sensors, computer devices, and systems that collect, store, transmit, and receive information over the network and are intended to control and interact with other devices and users [19].

In the future, the number of "things" connected to the Internet is expected to be higher than 5 per person. In 2003, about 6.3 billion people lived in the world and about 500 million devices were connected to the internet, which gives 0.08 devices per person. With the rapid growth in sales of smartphones, tablets and computers, the number of connected devices grew to 12.5 billion in 2010, with a population increase to 6.8 billion, making 1.84 devices per person. According to Cisco IBSG estimates, IoT was "born" between 2008 and 2009 when the number of devices connected to the Internet per person exceeded 1. It is estimated that 7.6 billion people will live in the world by the end of 2020 and the number of devices connected to the Internet will grow to more than 6 per person [20].

\subsubsection{Big Data Concept}

The Big data concept refers to a collection of large and complex datasets that, with classical databases and tools, are difficult to analyze and manage. One definition describes this concept as "any data set that does not fit into Excel spreadsheets" [21]. The Internet of Things, Big Data
Concept and Smart Cities are closely interconnected. Data in smart cities is generated through a large collection of sensors, databases, emails, websites and social media, and it is estimated that the city generates more than $2.5 \times 10^{18}$ bytes of data per day [6]. The challenges of the Big Data concept include their visualization, mining, analysis, storage, recording, searching and sharing, so they require new approaches of processing to enable better decisionmaking, search, optimization and insight into the process itself.

The simplest way to define a Big Data concept is with 3V: Volume, Velocity and Variety. Volume represents their large amount, which is collected, processed and made available for analysis, velocity involves the continuous collection of large amounts of data in real-time, and variety indicates that data is available in different forms and sources [19]. To satisfy the growth of data volumes, new techniques and methods of managing and integrating these data, their visualizations and special algorithms for their processing are emerging. In terms of data volume itself, new storage solutions are based on virtual clouds that reduce data processing and management costs and ensure cost-effectiveness and usability [22].

\section{SENSOR TECHNOLOGY AND APPLICATIONS IN SMART CITIES}

Smart cities can create efficient and smart services available to the public and authorities using sensor technology and platforms that will allow the sharing, storage and management of collected information. Sensors used in smart cities are divided into 4 basic groups: positional, pressure and air movement sensors, motion sensors and sound sensors. Sensors connected to the Internet (IoT) form the basis of collecting information in cities for monitoring and managing urban activities and making real-time decisions [19]. There is no universal sensor system for the entire city, but today we have sensor systems for the specific needs of the environment in which they operate. One of the main problems is that there is still no standard that these sensor systems must meet.

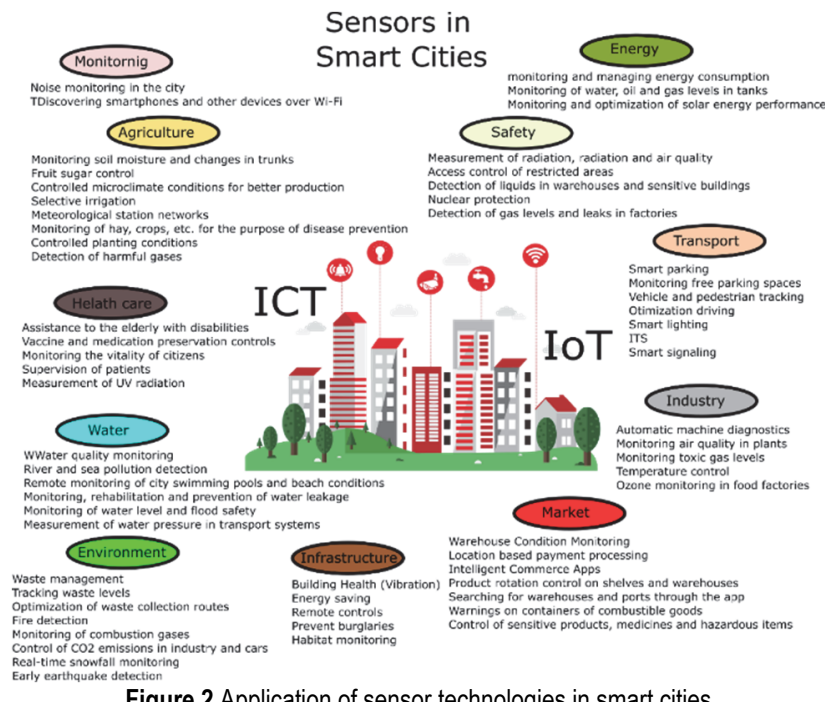

Figure 2 Application of sensor technologies in smart cities

Nowadays, wearable sensors are increasingly being used. Integrating information collected through wearable 
sensors, such as smartphones and their applications, can provide the city with valuable information about the movements and behavior of its users. Besides, sensor systems can be used to provide traffic and free parking spaces information, thereby reducing driving stress, losing fuel, reducing air pollution and increasing economic productivity. One of the most widespread innovations in urban infrastructure is smart public lighting with built-in motion sensors and energy-saving LED bulbs. Also, smart buildings are increasingly present today, which with their sensors, produce more energy than they consume. In addition to the above, there are numerous possibilities for the application of sensor technologies for smart cities, and some of them are shown in Fig. 2.

\section{THE CALLENGES OF DEVELOPING SMART CITIES}

The challenges of smart city development include many aspects such as cost, efficiency, sustainability, connectivity, security, and are conditioned by various factors such as the natural environment, government policy, the economy and social communities. One of the key challenges of smart cities is resilience to disasters and failures that can occur for many reasons, such as failure of ICT solution, power failure or ignorance of staff. Information and infrastructure security are also an important challenge in this concept. Every smart city must consider the answer to these challenges listed in Tab. 1.

Table 1 Challenges of smart city developmen

\begin{tabular}{|c|c|}
\hline Challenge & Impact \\
\hline ICT infrastructure & $\begin{array}{l}\text { Reliable, stable and fast network access is the basis of integration of information systems in the city. Digital } \\
\text { infrastructure needs to be established before all other components and must be reliable and prone to constant } \\
\text { changes and upgrades [23]. One of the challenges are the people and their proper education, knowledge and } \\
\text { skills in the use of technology. }\end{array}$ \\
\hline Security and privacy & $\begin{array}{l}\text { Collecting large amounts of data, including personal information, poses the issue of privacy as one of the } \\
\text { fundamental challenges in a smart city system. Extensive security access to sensitive data at all levels needs to } \\
\text { be ensured, to increase citizens' confidence in using the system }\end{array}$ \\
\hline Big Data Management & $\begin{array}{l}\text { The big data management system must be reliable and flexible and should not fall out of function. Constantly } \\
\text { generating, collecting, processing and storing of mass heterogeneous data from numerous sensors has its internal } \\
\text { challenges; however, the large amount of data is extremely useful for a successful initiative. }\end{array}$ \\
\hline Costs & $\begin{array}{l}\text { A smart city requires the establishment of huge infrastructure and large financial resources are needed to make } \\
\text { this system sustainable. Many sensors, network and computing devices are needed to connect the system and } \\
\text { the end-user. A significant cost is also posed by ICT professionals and other people who work on implementing } \\
\text { and later maintaining the system itself. }\end{array}$ \\
\hline Efficiency and availability & $\begin{array}{l}\text { The availability challenge is directly proportional to the complexity of the system itself. The massive amount of } \\
\text { data that is generated makes availability and efficiency one of the critical challenges of implementation [23]. In } \\
\text { a functioning society, citizens must be informed and have access to much information (services). Open data } \\
\text { significantly reduces citizens' time and money when doing their jobs. }\end{array}$ \\
\hline Sociological adaptation & $\begin{array}{l}\text { In a smart city, there is a challenge associated with inequality, digital divisions and changing cultural habits. } \\
\text { The social adaptation of such a system requires a change in the social habits of citizens as well as the city } \\
\text { government. }\end{array}$ \\
\hline Application development & $\begin{array}{l}\text { For citizens to make the most of the benefits that smart cities provide, faster development of new and innovative } \\
\text { applications must be ensured, otherwise, citizens' dissatisfaction with slow development can appear. }\end{array}$ \\
\hline Adaptability & $\begin{array}{l}\text { Here we are talking about the ability to prepare and adapt to changing conditions and recover quickly from the } \\
\text { effects of an attack, accident or natural disaster. If the digital infrastructure system fails or becomes } \\
\text { compromised, serious disruption to society and the economy can occur. }\end{array}$ \\
\hline Integration & $\begin{array}{l}\text { Instead of seeing people, networks, analytics tools, and platforms as separate entities, they need to be combined } \\
\text { into one. This will save time and money and in the long run, lead to much more efficient smart solutions. It is } \\
\text { necessary to understand how each aspect functions separately and how it uses data }\end{array}$ \\
\hline Environment & $\begin{array}{l}\text { Turning an existing city towards a smart one needs to meet more requirements than building a city in the green } \\
\text { area. The most important thing is to identify the weak areas that need the most attention. Integrating legacy } \\
\text { isolated systems to make a city fully effective can be a significant problem. }\end{array}$ \\
\hline
\end{tabular}

\section{THE ROLE OF GEOSCIENCES IN THE DEVELOPMENT OF SMART CITIES}

In addition to the ICT, IoT and Big Data concepts, geolocation and spatial data are one of the key drivers of successful development and decision making [24]. With the advancement and innovation of geospatial technologies, geosciences led by geomatics and geographic information systems (GIS) are becoming key drivers for the development of new smart applications within the Smart City concept.

Geomatics and GIS are often not identified as key components of a smart city, however, their use is inevitable for the successful implementation of the concept regarding the use of spatial applications in smart city management tools and services provided to users. Effective delivery of services based on the real needs of users requires adequate control and management systems that will provide timely and accurate supply, with location and the ability to understand the environment as key factors in the process.
Such systems must strive for speed, mobility, flexibility and be adaptable to changes in emergencies [24], and GIS systems are an ideal platform for such needs. GIS systems are increasingly used in private and public institutions to display spatial data and to conduct analyses across different thematic layers, often relying on aerial data (drones, aerophotogrammetry, etc.), satellite data and other sensors for remote sensing to obtain an up-to-date picture of the physical world. These technologies enable the acquisition of various skills, monitoring and management of land and other resources and alleviating various aspects of risk in everyday life. The rapid and constant development of technologies such as GIS, GNSS, remote sensing, web services and location services have led to tools that can support innovative management, government and citizen solutions in line with the goals of the smart city initiative. By implementing GIS into the planning and management aspects, organizations become smarter and increase their ability to provide better services to citizens while enabling city authorities to run the city more efficiently [25]. GIS 
technology is the key to successful urban planning because it enables 3D modeling and visualization of project and change detections on urban surfaces in an easy way. An efficient and sustainable GIS is the basis of conceptualizing, planning, developing and building infrastructure considering environmental factors, soil types, predicting the impact of natural disasters, analyzing historical data and more. We are currently in a time when urban spatial data is growing rapidly, and city governments are looking for better ways to access this data to improve city governance by giving insight into all the data collected and enabling citizens to participate in the decision-making process. To achieve this, GIS has been recognized as a powerful tool that enables the management, integration, analysis and visualization of large amounts of data and is essential for achieving the city's sustainability in the future [26].

One of the main features of smart cities is the efficient transport system (ITS). GNSS sensors are the basis for their development and enables them to design smart routes and more efficient transportation within the city. In addition to transportation, GNSS has several applications in other aspects of the smart city such as health, urban development, civil security, tourism, etc. Open access to GPS data has encouraged the development of location services and applications for managing and controlling goods, resources and infrastructure, and new GNSS constellations such as Galileo will provide a better understanding of city dynamics and responses to citizens' needs. They should result in better signal coverage and less sensitivity to interference in urban canyons while providing better positioning and precision with smaller and less expensive devices. With GNSS systems, cities are increasingly using new Wi-Fi-based indoor positioning solutions that are opening a new range of mapping services and applications.

Mobile laser scanning devices are also finding use in smart city initiatives to meet the need for high-resolution $3 \mathrm{D}$ data. They enable quick and economic collection of large amounts of data across a large area that is used for a variety of applications, from transportation to land management [24]. Other technologies for collecting such data are mobile mapping systems, which allow data to be collected in previously unavailable areas, expanding the possibilities of digitizing the environment in both open and indoor spaces. The 3D data obtained are used to create 3D models, especially buildings, which are being imposed as one of the most important components of urban planning. LiDAR and photogrammetry are the most widely used 3D mapping technologies for smart cities, providing high accuracy models. Increased urbanization and uncontrolled development of urban infrastructure are the main reasons for the increasing need for 3D models of cities. Such models have many advantages such as detailed perception of city space, creation of information systems of buildings in the city, better monitoring of energy consumption, development of solar systems, etc. [27]. They also support tasks such as spatial analysis, planning and renovation, making them a new tool for communication between city and government institutions and service providers to citizens. The application of such technologies also entails experts who will collect 3D data from point cloud and georeference them to intelligent models of urban infrastructure and environment. Also, there are many diverse types of spatial data (points, polygons, etc.), coordinate systems, levels of detail and reliability that require expert approaches to address inconsistencies.

With the applications of geoscience in smart cities mentioned above, some other applications are also used such as digital relief models, integrated automatic and semi-automatic processing of laser scanner point clouds, processing and acquisition of UAV images, change detection from aerial and satellite mission, development of 4D cadaster and land registry in cities, development of land use maps, historical and other thematic maps, use of GIS for better ITS management, climate data, health, waste, water, e-services and other aspects of urban importance [28]. Maps, as a product of geoscience work, are an essential tool, not only for our daily lives but also for the sustainable growth of urban planning. As cities expand every day, even the most accurate maps will quickly become obsolete. The advancement of geospatial technologies, and most of all remote sensing, has provided tools for up-to-date and reliable maps, and today on this basis, a new term - "smart maps" - is being mentioned. Smart maps allow citizen involvement and interaction and are designed as digital maps that capture a wide range of data and information that can be updated and upgraded with new layers as quickly and easily as possible [29].

The development of a smart city and its infrastructure cannot be achieved without an adequate spatial data infrastructure (SDI). The concept of a smart city requires an operational infrastructure of spatial data and a unique database of collected data, with all data having to use the same standard and specifications to avoid redundant and intertwined data. With SDI and GIS, remote sensing is nowadays increasingly becoming one of the useful techniques for implementing the concept of a smart city at all stages of project establishment. They help with decision making, monitoring urban development and land changes, they enable visualization and assessment of environmental impact and identifying the best locations for new infrastructure. The great rise and application of these methods is the result of the technological advancement of remote sensing sensors, but also their increasing availability (e.g. Copernicus data).

\section{CONCLUSION}

The urbanization process has affected most European and world cities, significantly increasing the need for better mobility, putting pressure on urban infrastructure and resources in terms of energy, food and water consumption. As a result, cities are looking for innovative solutions that will improve quality of life and ensure economic growth. These cities are called smart cities, and they are still just a concept with numerous definitions that deal with its components and factors. A smart city can have one or more smart components including transportation, infrastructure, energy, healthcare, government, water and waste management. ICT with the Internet of Thing and Big Data concept is the key to implementing a smart city and its sustainability. A smart city must also become spatially sustainable by developing concepts and services where the spatial information (location) will be available to city authorities and citizens. Therefore, the integration of ICT with geospatial technologies is essential. Such integration is revolutionizing, especially in terms of city planning, development and management. Geosciences, led by geomatics, as a science that integrates satellite techniques, cartography and GIS, nowadays exceed their standard 
application and enter the spheres of urban and regional planning and management and become a viable decisionmaking tool in everyday life, and essential for implementing the concept of smart cities. An efficient spatial data infrastructure enables a wide range of methods and technologies for the development and implementation of a smart city, so geodesy and geoinformatics, due to increasing interdisciplinarity of other sciences, must take their place in this concept and its understanding is crucial for the sustainability of the profession.

\section{REFERENCES}

[1] Chaurabi, H., Nam, T., Walker, S., Gil-Garcia, J., Mellouli, S., Nahon, K., Pardo, T., \& Scholl, H. J. (2012). Understanding Smart Cities: An Integrative Framework. Proceedings of the 2012 45th Hawaii International Conference on System Sciences. IEEE Computer Society, 2289-2297. https://doi.org/10.1109/HICSS.2012.61 5

[2] United Nations Economic and Social Council. (2016). Smart cities and infrastructure: Report of the Secretary-General. United Nations.

[3] Seto, K. C., Dhakal, S., Bigio, A., Blanco, H., Delgado, G. C., Dewar, D., Huang, L., Inaba, A., Kansal, A., Lwasa, S., McMahon, J. E., Müller, D. B., Murakami, J., Nagendra, H., \& Ramaswami, A. (2014).Climate Change 2014: Mitigation of Climate Change. Contribution of Working Group III to the Fifth Assessment Reportof the Intergovernmental Panel on Climate Change: Human Settlements, Infrastructure and Spatial Planning. Cambridge University Press.

[4] United Nations Commission on Science and Technology for Development. (2016). Inter-sessional Panel 2015-2016: Issues on Smart Cities and Infrastructure. Budapest, Hungary. Retrieved from https://unct ad.org/meeting/cstd2015-2016-inter-sessional-panel

[5] International Telecommunicatin Union (ITU-T). (2014). Smart sustainable citites: An analysis of definitions. ITU-T Focus Group on Smart Sustainable Cities. Tecnical Report. Geneva.

[6] Mohanty, S. P. (2016). Everything you wanted to know about smart cities: The Internet of things is the backbone. IEEE Consumer Electronics Magazine, 5, 60-70. https://doi.org/ 10.1109/MCE.2016.2556879.

[7] Bakıc1, T., Almirall, E., \& Wareham, J. A. (2013). Smart City Initiative: the Case of Barcelona. Journal of the Knowledge Economy, 4, 135-148. https://doi.org/10.1007/s13132-012-0084-9

[8] Cohen, B. (2018). Blockchain Cities and the Smart Cities Wheel. Medium.

[9] Gil-García, J. R. \& Pardo, T. A. (2005). E-government success factors: Mapping practical tools to theoretical foundations. Government Information Quarterl, 22(2), 187216. https://doi.org/10.1016/j.giq.2005.02.001

[10] Odendaal, N. (2003). Information and communication technology and local governance: Understanding the difference between cities in developed and emerging economies. Computers, Environment and Urban Systems, 27(6), 585-607.

[11]Belissent, J. (2011). The Core of a Smart City Must Be Smart Governance. Cambridge, MA: Forrester Research, Inc. Retrieved from https://www.forrester.com/webinar/The + Core + Of + A + Smart+City + Must+Be+Smart+Governance/E-WEB7738\#

[12] Giffinger, R., Kramar, H., \& Haindl, G. (2008). The role of rankings in growing city competition. Urban Research \& Practice, 3(3), 299-312.

https://doi.org/10.1080/17535069.2010.524420
[13] Jarvinen, S., Kramar, H., \& Haindl, G. (2015). Smart City Research Highlights. VTT Technical Research Centre of Finland Ltd.

[14] Tips, B. \& Taft, J. (2010). Substation Automation Solutions for Utility Operations. Cisco. https://www.yumpu.com/en/ document/read/41846299/substation-automation-solutionsfor-utility-operations-cisco

[15] Hoornweg, D. \& Bhada-Tata, P. (2012). What a Waste: A Global Review of Solid Waste Management. Urban development series, 15 . World Bank.

[16] Jayasinghe, S. (2015). Social determinants of health inequalities: towards a theoretical perspective using systemsscience. International Journal for Equity in Health, 14, 71. https://doi.org/10.1186/s12939-015-0205-8

[17]Bosch. (2018). Better quality of life for residents and users. Smart Building. https:/www.bosch.com/products-andservices/connected-products-and-services/smart-building/

[18] Ahlgren, B., Hidell, M., \& Ngai, E. (2016). Internet of Things for Smart Cities: Interoperability and Open Data. IEEE Internet Computing, 20(6), 52-56. https://doi.org/10.1109/MIC.2016.124

[19] Song, H., Srinivasan, R., Sookoor, T., \& Jeschke, S. (2017). Smart Cities: Foundations, Principles, and Applications (1st ed.). Wiley.

[20]Evans, E. D. (2011). The Internet of Things How the Next Evolution of the Internet Is Changing Everything. Cisco Internet Business Solutions Group (IBSG), Cisco Systems. https://www.cisco.com/c/dam/en_us/about/ac79/docs/innov /IoT IBSG 0411FINAL.pdf

[21]Batty, M. (2013). Big data, smart cities and city planning. Dialogues in Human Geography, 3(3), 274-279. https://doi.org/10.1177/2043820613513390

[22]Deloitte. (2015). Smart Cities Big Data. https://www2.deloitte.com/content/dam/Deloitte/za/Docum ents/risk/ZA_SmartCitiesBig\%20Data_\%20finale.pdf

[23] Bawany, N. Z. \& Shamsi, J. A. (2015). Smart City Architecture: Vision and Challenges. International Journal of Advanced Computer Science and Applications, 6(11), 246-255. https://doi.org/10.14569//JACSA.2015.061132

[24]Daniel, S. \& Doran, M. A. (2013). GeoSmartCity: Geomatics contribution to the Smart City. Proceedings of the 14th Annual International Conference on Digital Government Research, 65-71. https://doi.org/10.1145/ 2479724.2479738

[25] Shah, N. (2016). Using GIS Tecnology for Smart Citites. Bureaucracy Today, 9, 33.

[26]Dangermond, J. (2015). Geospatial Technology and the Future of the City. ArcNews.

[27] Shukla, S. \& Bajapi, R. (2017). An application of 3D Laser Scanning for Infrastructural Mapping and its Comparison with Photogrammetry. GIS Resources, 2, 9-12.

[28] Gruen, A. (2013). Next generation Smart Cities - the role of Geomatics. International Workshop on "Global Geospatial Information".

[29] Martinez, A. J. (2017). Geospatial Information to develop sustainable cities in India. GIS resources, 2, 15-17.

\section{Contact information}

Zvonimir NEVISTIĆ, M.Sc. in geodesy and geoinformatics, Assistant

(Corresponding author)

Faculty of geodesy, Zagreb University,

Kačićeva 26, 10000 Zagreb

E-mail: znevistic@geof.hr

Željko BAČıć, PhD, Professor

Faculty of geodesy, Zagreb University,

Kačićeva 26, 10000 Zagreb

E-mail: zbacic@geof.hr 